\title{
ORIGINAL
}

\section{Management and outcomes of acute respiratory distress syndrome patients with and without comorbid conditions}

\author{
Elie Azoulay ${ }^{1 *} \mathbb{D}$, Virginie Lemiale1, Bruno Mourvillier², Maite Garrouste-Orgeas ${ }^{3}$, Carole Schwebel ${ }^{4}$, \\ Stéphane Ruckly ${ }^{5}$, Laurent Argaud ${ }^{6}$, Yves Cohen $^{7}$, Bertrand Souweine ${ }^{8}$, Laurent Papazian ${ }^{9}$, Jean Reignier ${ }^{10}$, \\ Guillaume Marcotte ${ }^{11}$, Shidasp Siami ${ }^{12}$, Hatem Kallel ${ }^{13}$, Michael Darmon ${ }^{1}$ and Jean-François Timsit ${ }^{14}$ \\ on behalf of the OUTCOMEREA Study Group
}

(c) 2018 Springer-Verlag GmbH Germany, part of Springer Nature and ESICM

\begin{abstract}
Rationale: The standard of care for patients with acute respiratory distress syndrome (ARDS) has been developed based on studies that usually excluded patients with major comorbidities.

Objectives: To describe treatments and outcomes according to comorbidities in patients with ARDS admitted to 19 ICUs (1997-2014).

Methods: Patients were grouped based on comorbidities. Determinants of day-28 mortality were identified by multivariable Cox analysis stratified on center.

Measurements and main results: Among 4953 ARDS patients, 2545 (51.4\%) had major comorbidities; the proportion with major comorbidities increased after 2008. Hematological malignancy was associated with severe ARDS and rescue therapies for refractory hypoxemia. COPD, HIV infection, and hematological malignancy were associated with a lower likelihood of invasive mechanical ventilation on the admission day. Admission-day SOFA score was higher in patients with major comorbidities, who more often received vasopressors, dialysis, or treatment-limitation decisions. Day-28 mortality was $33.7 \%$ overall, $27.2 \%$ in patients without major comorbidities, and $31.1 \%$ (COPD) to $56 \%$ (hematological malignancy) in patients with major comorbidities. By multivariable analysis, mortality was lower in patients with COPD and higher in those with chronic heart failure, solid tumors, or hematological malignancies. Mortality was independently associated with $\mathrm{P}_{\mathrm{a}} \mathrm{O}_{2} / \mathrm{F}_{\mathrm{i}} \mathrm{O}_{2}$ and $\mathrm{PaCO}_{2}$ on day 1 , ARDS of pulmonary origin, worse SOFA score, and ICUacquired events.
\end{abstract}

Conclusions: Half the patients with ARDS had major comorbidities, which were associated with severe ARDS, multiple organ dysfunction, and day-28 mortality. These findings do not support the exclusion of ARDS patients with severe comorbidities from randomized clinical trials. Trials in ARDS patients with whatever comorbidities are warranted.

Keywords: Acute respiratory failure, Cancer, Mortality, Leukemia, Ventilation

\footnotetext{
*Correspondence: elie.azoulay@aphp.fr

${ }^{1}$ Medical Intensive Care Unit, AP-HP, Saint-Louis hospital, ECSTRA

Team, Biostatistics and CLINICAL EPIDEMIOLOGY, UMR 1153 (Center of Epidemiology and Biostatistic Sorbonne Paris Cité, CRESS), INSERM,

Paris Diderot Sorbonne University, Paris, France

Full author information is available at the end of the article
} 


\section{Introduction}

Research into acute respiratory distress syndrome (ARDS) has provided new pathophysiological insights that have major clinical implications $[1,2]$. For instance, evidence that ventilator-induced lung injury is a major contributor to ARDS $[3,4]$ prompted the development of new protective ventilation strategies and of new mechanical ventilation (MV) guidelines [5-7]. To date, no pharmacological treatments have been proven effective in ARDS. However, in addition to MV for acute respiratory failure, treatments must be given not only for the condition associated with the acute or subacute, direct or indirect lung insult that caused ARDS to develop [8], but also for any preexisting comorbid conditions. In some cases, chronic comorbidities, such as malignancies, contribute to the development of ARDS, whereas in others they may increase the patient's vulnerability to complications of ARDS or treatments [9]. In patients with ARDS, the presence of comorbidities is associated with increased mortality. A prospective study of 107 patients found that independent predictors of death included active malignancy, cirrhosis of the liver, HIV infection, and transplantation, in addition to age above 65 years [10]. However, since its publication in 1998, no other large study has investigated potential differences in ARDS outcomes according to the comorbidity profile. The findings from this study [10] led to the exclusion of patients with major comorbidities from subsequently performed clinical trials and epidemiological studies of mortality rates.

Excluding patients with major comorbidities from studies of ARDS leads to selection bias and limits the external validity of the findings. Another concern is that the sickest patients may be deprived of potentially beneficial treatments if they are not included in trials [11]. Moreover, knowledge about the predictors of mortality in patients with ARDS and major comorbidities may help to identify targets for improvement in other patients [12-15]. For instance, the cause of ARDS is closely associated with mortality in patients with cancer [16-20] but not in the overall population of patients with ARDS [1], hampering generalizability of the findings in unselected patients. For instance, the $12.5 \%$ unexpected rate of invasive aspergillosis in autopsy studies of non-immunocompromised patients with ARDS may be related to a lack of knowledge transfer from the immunocompromised literature [20]. Similarly, the deleterious effects of non-invasive ventilation followed by delayed invasive mechanical ventilation in patients with severe hypoxemia were first noticed in immunocompromised patients $[18,21]$ before being documented in unselected patients $[15,22]$.

Our primary objective here was to determine whether the prevalence of comorbidities in an unselected

\section{Take home message}

Half the ARDS patients have major comorbidities and this proportion increased over time. The differences in presentation and outcome of ARDS between patients with and without major comorbidities challenge the acceptability of confining studies to relatively healthy patients.

population with ARDS was sufficiently high to warrant concerns about the validity and acceptability of studies confined to patients without comorbidities. Our secondary objective was to determine whether the presentation, management, and outcomes of ARDS varied significantly according to the comorbidity profile; such differences would further support the need for studies in unselected patients and may identify new pathophysiological hypotheses and new areas for therapeutic improvements. To achieve these objectives, we retrospectively analyzed prospectively collected data. We estimated the adjusted impact of comorbidities on the characteristics and outcomes of ARDS.

\section{Patients and methods}

We conducted a retrospective analysis of the French multicenter prospective observational cohort in the OutcomeRea $^{\mathrm{TM}}$ database [23]. The Clermont-Ferrand ethics committee approved the study. Adults admitted to the 19 participating ICUs were prospectively included from January 1, 1997, to July 9, 2014. Details of the database are provided in the online-only supplement.

Among patients receiving invasive MV within the first three ICU days, we identified those meeting the Berlin definition of ARDS [8]: respiratory symptoms with onset within the last 7 days and bilateral chest radiograph opacities not fully explained by heart failure or fluid overload and $\mathrm{PaO}_{2} / \mathrm{FiO}_{2}$ ratio $\leq 300$ with $\mathrm{PEEP} \geq 5 \mathrm{~cm} \mathrm{H}_{2} 0$. All the items from the Berlin definition have been collected in the database since its creation. Rescue strategies included nitric oxide, prone positioning and ECMO. The variables listed in the tables and figures were collected prospectively and audited. The main outcome was allcause day- 28 mortality. Additional details are available in the online-only supplement.

Major comorbidities were identified using the Knaus classification from the APACHEII [24], as described previously $[25,26]$, and categorized based on the list of exclusion criteria used in all clinical therapeutic trials in ARDS reported between 2005 and 2015 (Fig. 1). The categories were as follows: chronic respiratory diseases; chronic heart disease; solid tumors; liver cirrhosis; immunodeficiency induced by drugs (used in transplant recipients or to treat inflammatory diseases); hematological malignancies; and HIV infection. Other conditions 


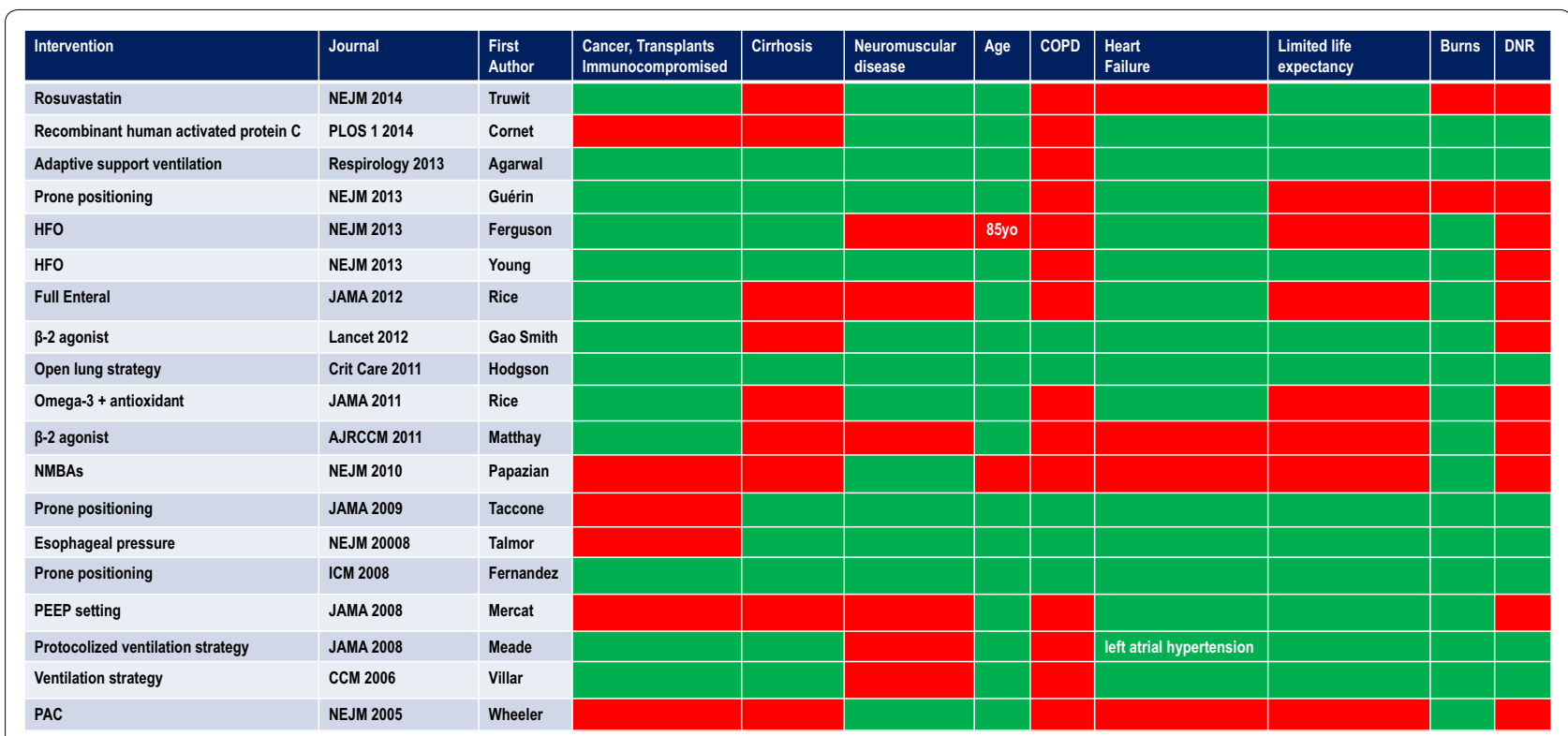

HFO, high-flow oxygen therapy; NMBAs, neuromuscular blocking agents; PAC, pulmonary artery catheter

Fig. 1 Systematic review of all therapeutic trials in ARDS published between 2005 and 2015. Comorbid conditions are displayed in red if they were exclusion criteria in the trial and in green if they were not [39-57]

such as diabetes, hypertension, and chronic kidney disease were not classified as major comorbidities.

ICU-acquired events were defined as previously reported. A medical error as the failure of a planned action to be completed as intended (i.e., error of execution) or the use of a wrong plan to achieve an aim (i.e., error of planning), and an adverse event as an injury caused by a medical intervention that resulted in harm [27.]

\section{Quality of the database}

For most of the study variables, the data capture software immediately ran an automatic check for internal consistency, generating queries that were sent to the ICUs for resolution before incorporation of the new data into the database. In each participating ICU, data quality was checked by having a senior physician from another participating ICU review a $2 \%$ random sample of the study data from alternate years. A 1-day-long data capture training course held once annually was open to all OUTCOMEREATM investigators and study monitors.

\section{Statistical analysis}

Quantitative variables are described as median and interquartile range and qualitative variables as $n$ (\%).

The primary objective of our study was to compare day-28 mortality in patients with versus without major comorbidities and across comorbidity groups. To identify variables associated with day- 28 mortality, we built univariate Cox regression models stratified by center. Clinically relevant variables and variables significantly associated with day- 28 mortality by univariate analysis were the lowest $\mathrm{P}_{\mathrm{a}} \mathrm{O}_{2} / \mathrm{F}_{\mathrm{i}} \mathrm{O}_{2}$ ratio categorized into categories adapted from the Berlin definition [6], pulmonary ARDS, SOFA score without respiratory points, use of inotropic drugs, hemodialysis, ICU-acquired events, ECMO, and $\mathrm{PCO}_{2}>50 \mathrm{mmHg}$. These variables were entered into multivariable models. Five missing values were imputed for $\mathrm{PCO}_{2}$ [28]. All variables entered in multivariate models were collected at ICU admission. Colinearity between variables and pairwise interactions were tested. Multivariate Cox regression was performed with stepwise selection. Each comorbidity category was forced into the model. Age was analyzed as a covariate and not a comorbidity. Survival models were censored at day 28. Patients who were lost to follow-up before day 28 were censored at hospital discharge.

Time trends in day-28 mortality in patients without comorbidities and in those with at least one comorbidity were evaluated with the Cochran-Armitage test. To evaluate the effect of $\mathrm{P}_{\mathrm{a}} \mathrm{O}_{2} / \mathrm{F}_{\mathrm{i}} \mathrm{O}_{2}$ ratio on day- 28 mortality, we built a multivariate Cox regression model stratified by center and adjusted on comorbidities, extra-respiratory SOFA score items, and worst $\mathrm{P}_{\mathrm{a}} \mathrm{CO}_{2}$ on day 1 . The Cox model was selected as it included time-dependent variables. A spline term on the $\mathrm{P}_{\mathrm{a}} \mathrm{O}_{2} / \mathrm{F}_{\mathrm{i}} \mathrm{O}_{2}$ ratio was used. ROC curve analysis was performed to assess how well the Berlin severity category on day 1 predicted day- 28 mortality. 
All statistical analyses were conducted with SAS 9.3 (SAS Institute, Cary, NC, USA). $P$ values $<0.05$ were considered statistically significant.

\section{Results}

\section{Patients}

Among the 19,019 adults admitted to the 19 participating ICUs throughout the 17.5-year recruitment period, 9804 (51.6\%) received MV within 3 days after ICU admission and, among these, 5465 (55.7\%) had $\mathrm{PaO}_{2} / \mathrm{FiO}_{2} \leq 300$ (Fig. 2), including 4953 who met criteria for ARDS and were included in the study. Of these 4953 patients, 2408 (48.6\%) had no major comorbidities, 1942 (39.2\%) had one major comorbidity, and $603(12.2 \%)$ had two or more major comorbidities. The most common comorbid conditions were chronic respiratory diseases $(n=948)$, followed by chronic heart failure $(n=673)$, solid tumors $(n=628)$, liver cirrhosis $(n=357)$, drug-related immunodeficiency $(n=256)$, hematological malignancies $(n=248)$, and HIV infection $(n=104)$. Table 1 reports the patient characteristics in the comorbidity groups.

\section{Day-28 mortality}

Day-28 mortality was 33.7\% (1667 deaths) overall, 27.2\% in patients with no comorbidities, and 31.1\% (COPD group) to $56 \%$ (hematological malignancies group) in

19019 patients admitted to the 19 participating ICUS (1996-2014)

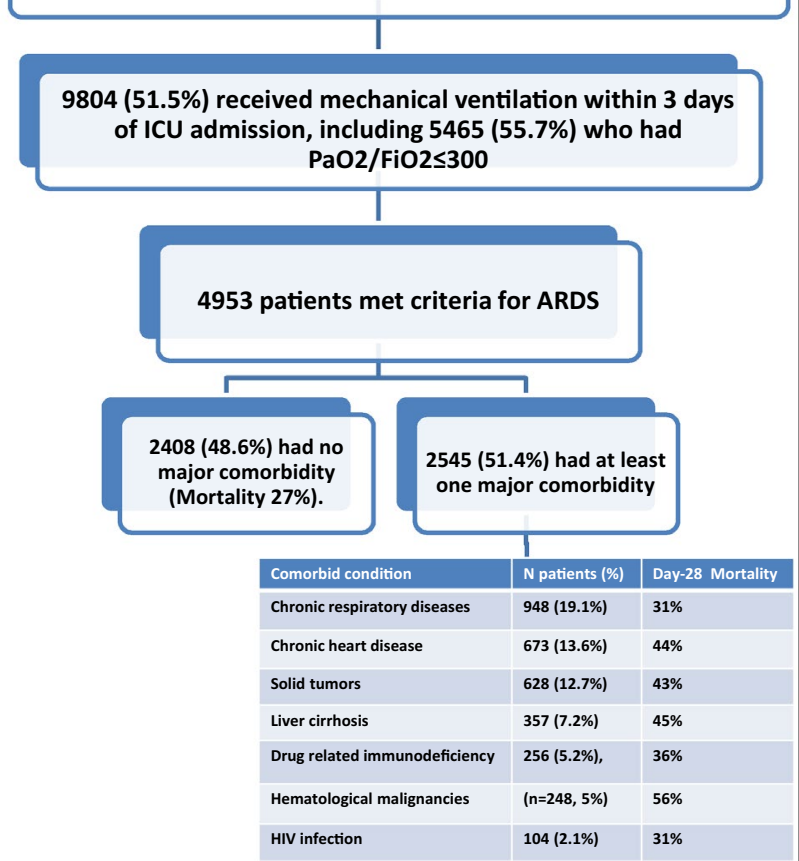

Fig. 2 Patient flow diagram; note that 603 patients had more than one comorbidity patients with at least one comorbidity (Table 1; Fig. 2). By multivariable analysis (Table 2), chronic heart failure, solid tumors, and hematological malignancies were independently associated with higher day-28 mortality, whereas COPD was associated with lower day- 28 mortality. A worse SOFA score and the occurrence of ICUacquired events were associated with higher day-28 mortality. Pulmonary ARDS was associated with lower day-28 mortality compared to extra-pulmonary ARDS. Finally, highest $\mathrm{PaCO}_{2}$ on day 1 independently predicted day-28 mortality.

According to the Berlin definition, 1864 (37.6\%) patients had mild, 2034 (41.1\%) moderate, and 1055 (21.3\%) severe ARDS. Day-28 mortality differed significantly across these three groups $(26.5,35.5$, and $46.6 \%$, respectively, $P<0.0001)$. However, the ability of the Berlin severity definition to predict day- 28 mortality was only fair on day 1 [area under the curve (AUC), 0.59] and day 2 (AUC, 0.61). $\mathrm{PaO}_{2} / \mathrm{F}_{\mathrm{i}} \mathrm{O}_{2}<100$ was significantly associated with day-28 mortality (Fig. 3). $\mathrm{PaCO}_{2}>50 \mathrm{mmHg}$ on day 1 was also significantly associated with day- 28 mortality [hazard ratio, 1.005/point; 95\% confidence interval (CI), 1.002-1.009; $P=0.003$ ).

\section{ARDS features according to comorbidities}

Of the 4953 patients, 1217 (24.6\%) had pulmonary ARDS (Table 1). Pulmonary ARDS was more common among patients with liver cirrhosis or immunodeficiency compared to patients without comorbidities. Invasive MV on day 1 was less common among patients with COPD, HIV infection, or hematological malignancies compared to patients without comorbidities. Patients with hematological malignancies more often had severe ARDS, and more often received rescue therapies for refractory hypoxemia (OR, 1.79; 95\% CI, 1.22-2.61; $P<0.01$ ). Finally, except in the group with respiratory diseases, the SOFA score at admission was higher in the groups with comorbidities, which also had greater use of vasopressors and renal replacement therapy, compared to the group without comorbidities.

\section{Treatment-limitation decisions}

Figure 4 displays the odds ratios (OR) for treatment-limitation decisions according to the comorbidity groups. Overall, treatment-limitation decisions taken within 2 days after ICU admission were significantly more common in patients with liver cirrhosis (OR, 1.94; $95 \%$ CI, 1.26-3.00; $P<0.01$ ), solid tumors (OR, 1.93; 95\% CI, $1.36-2.75 ; P<0.01)$, or hematological malignancies (OR, $1.79 ; 95 \% \mathrm{CI}, 1.06-3.01 ; P=0.03)$. As the ICU stay length increased, compared to patients without comorbidities, those with comorbidities other than HIV infection or drug-related immunodeficiency increasingly received 
Table 1 Patient characteristics in the groups with and without comorbidities

\begin{tabular}{|c|c|c|c|c|c|c|c|c|}
\hline & $\begin{array}{l}\text { No comorbid- } \\
\text { ity }(n=2408)\end{array}$ & $\begin{array}{l}\text { COPD } \\
(n=948)\end{array}$ & CHF $(n=673)$ & $\begin{array}{l}\text { Solid Tumor } \\
(n=628)\end{array}$ & $\begin{array}{l}\text { Cirrhosis } \\
(n=357)\end{array}$ & $\begin{array}{l}\text { Drug-related } \\
\text { immuno- } \\
\text { deficiency } \\
(n=256)\end{array}$ & $\begin{array}{l}\text { Hemato- } \\
\text { logical } \\
\text { malignancy } \\
(n=248)\end{array}$ & $\begin{array}{l}\text { HIV infection } \\
(n=104)\end{array}$ \\
\hline $\begin{array}{l}\text { ICU admission } \\
\text { after } 2008\end{array}$ & 862 (35.8) & $353(37.2)$ & 265 (39.4) & $254(40.4)^{c}$ & $154(43.1)^{c}$ & $125(48.8)^{c}$ & $119(48)^{c}$ & $31(29.8)$ \\
\hline $\begin{array}{l}\text { SOFA score on } \\
\text { day } 1\end{array}$ & $7[5 ; 10]$ & $7[5 ; 10]$ & $8[6 ; 11]^{c}$ & $8[5 ; 10]$ & $10[7 ; 14]^{c}$ & $8[6 ; 11]^{c}$ & $10[7 ; 13]^{c}$ & $9[6 ; 11]^{c}$ \\
\hline $\begin{array}{l}\text { Pulmonary } \\
\text { ARDS }\end{array}$ & 1669 (69.3) & $723(76.3)$ & $438(65.1)$ & $373(59.4)$ & $250(70)$ & 179 (69.9) & 219 (88.3) & $91(87.5)$ \\
\hline $\begin{array}{l}\text { Invasive MV on } \\
\text { day } 1\end{array}$ & 2036 (84.6) & $740(78.1)^{c}$ & $554(82.3)$ & 495 (78.8) & 271 (75.9) & $193(75.4)$ & $156(62.9)^{c}$ & $66(63.5)^{c}$ \\
\hline Severe ARDS & 491 (20.4) & $201(21.2)$ & $129(19.2)$ & $139(22.1)$ & $75(21)$ & $63(24.6)$ & $63(25.4)^{c}$ & $28(26.9)$ \\
\hline $\begin{array}{l}\text { Highest } \mathrm{PaCO} 2 \\
\text { at day } 1\end{array}$ & $39(34-46)$ & $47(38-62)^{c}$ & $40(32-48)$ & $40(34-47)$ & $37(0-44)^{c}$ & $39(33-47)$ & $38(32-47)$ & $42(34-50)$ \\
\hline \multicolumn{9}{|c|}{ Treatments during the ICU stay } \\
\hline Vasopressors & $1545(64.2)$ & $678(71.5)^{c}$ & $544(80.8)^{c}$ & $479(76.3)^{c}$ & $284(79.6)^{c}$ & $189(73.8)^{c}$ & $216(87.1)^{c}$ & $76(73.1)^{c}$ \\
\hline $\begin{array}{l}\text { Renal } \\
\text { replace- } \\
\text { ment } \\
\text { therapy }\end{array}$ & $429(17.8)$ & $164(17.3)$ & $198(29.4)^{c}$ & $134(21.3)^{c}$ & $110(30.8)^{c}$ & $84(32.8)^{c}$ & $98(39.5)^{c}$ & $34(32.7)^{c}$ \\
\hline $\begin{array}{l}\text { Rescue strat- } \\
\text { egies }\end{array}$ & $209(8.7)$ & $91(9.6)$ & $45(6.7)$ & $58(9.2)$ & $31(8.7)$ & $27(10.5)$ & $36(14.5)$ & $18(17.3)$ \\
\hline Nitric oxide & $131(5.4)$ & $69(7.3)^{c}$ & $35(5.2)$ & $44(7)$ & $18(5)$ & $16(6.3)$ & $24(9.7)^{c}$ & $14(13.5)^{c}$ \\
\hline $\begin{array}{l}\text { Prone posi- } \\
\text { tioning }\end{array}$ & $111(4.6)$ & $41(4.3)$ & $13(1.9)^{c}$ & $26(4.1)$ & $15(4.2)$ & $15(5.9)$ & $18(7.3)$ & $8(7.7)$ \\
\hline ECMO & $32(1.3)$ & $3(0.3) c$ & $4(0.6)$ & $3(0.5)$ & $3(0.8)$ & $2(0.8)$ & $1(0.4)$ & $2(1.9)$ \\
\hline \multicolumn{9}{|c|}{ Treatment-limitation decisions ${ }^{a}$} \\
\hline $\begin{array}{l}\text { On day } 1 \text { or } \\
\text { day } 2\end{array}$ & $101(4.2)$ & $39(4.1)$ & $36(5.3)$ & $49(7.8)^{c}$ & $28(7.8)^{c}$ & $12(4.7)$ & $18(7.3)^{c}$ & $2(1.9)$ \\
\hline $\begin{array}{l}\text { At any time } \\
\text { during the } \\
\text { ICU stay }\end{array}$ & $335(13.9)$ & $187(19.7)^{c}$ & $136(20.2)^{c}$ & $164(26.1)^{c}$ & $84(23.5)^{c}$ & $45(17.6)$ & $59(23.8)$ & $14(13.5)$ \\
\hline Reintubation & $464(19.3)$ & $217(22.9)^{c}$ & $133(19.8)$ & $108(17.2)$ & $57(16)$ & $44(17.2)$ & $31(12.5)^{c}$ & $21(20.2)$ \\
\hline $\begin{array}{l}\text { ICU-acquired } \\
\text { events }^{b}\end{array}$ & $1136(47.2)$ & $525(55.4)^{c}$ & $391(58.1)^{c}$ & $345(54.9)^{c}$ & $213(59.7)^{c}$ & $163(63.7)^{c}$ & $141(56.9)^{c}$ & $49(47.1)$ \\
\hline VAP & 277 (11.5) & $161(17)$ & 78 (11.6) & 87 (13.9) & $49(13.7)$ & $37(14.5)$ & $44(17.7)$ & $17(16.3)$ \\
\hline $\begin{array}{l}\text { Day-28 mor- } \\
\text { tality }\end{array}$ & $655(27.2)$ & $295(31.1)^{c}$ & $293(43.5)^{c}$ & $271(43.2)^{c}$ & $162(45.4)^{c}$ & $91(35.5)^{c}$ & $139(56)^{c}$ & $33(31.7)$ \\
\hline
\end{tabular}

Note: 603 patients had more than one comorbidity

COPD chronic obstructive pulmonary disease, CHF chronic heart failure, HIV human immunodeficiency virus, ICU intensive care unit, SOFA sequential organ function assessment, $\mathrm{MV}$ mechanical ventilation, $A R D S$ acute respiratory distress syndrome, $\mathrm{PaCO}_{2}$ partial pressure of carbon dioxide in arterial blood, $E C M O$ extracorporeal membrane oxygenation, VAP ventilator-associated pneumonia

a Defined as decisions to withhold or withdraw life-supportive treatments

b Defined as events that were not expected at ICU admission but may affect outcomes, i.e., bleeding, myocardial or mesenteric infarction, atelectasis, cardiac arrest, arrhythmia requiring cardioversion, pulmonary embolism, drug allergy, seizures, medical error, hypoglycemia, and pericarditis requiring drainage

c $P<0.05$ compared to patients with no major comorbidities

treatment-limitation decisions. Last, among patients who died, those with COPD or solid tumors were significantly more likely to have treatment-limitation decisions.

\section{Time trends}

As compared to ICU admission between 1997 and 2007, ICU admission after 2008 was more common in patients with drug-related immunodeficiency (OR, 1.71 ; 95\% CI, 1.32-2.22; $P<0.01$ ), hematological malignancies (OR, 1.65; 95\% CI, 1.27-2.15; $P<0.01$ ), liver cirrhosis (OR, 1.36; 95\% CI, 1.09-1.70; $P<0.01$ ), or solid tumors (OR, 1.22; 95\% CI, 1.02-1.46; $P=0.03$ ), compared to patients with no comorbidities. Age was not different between the two time periods. In patients 
Table 2 Multivariate analysis of factors independently associated with day-28 mortality in patients with ARDS (Cox model stratified on center)

\begin{tabular}{|c|c|c|}
\hline Variable & Hazard ratio (95\% confidence interval) & $P$ value \\
\hline \multicolumn{3}{|l|}{ Comorbid conditions } \\
\hline $\begin{array}{l}\text { Chronic respiratory disease } \\
\text { Chronic heart failure } \\
\text { Liver cirrhosis } \\
\text { Solid tumor } \\
\text { Drug-related immunodeficiency } \\
\text { Hematological malignancy } \\
\text { HIV infection }\end{array}$ & $\begin{array}{l}0.824(0.721-0.942) \\
1.492(1.308-1.701) \\
1.124(0.951-1.329) \\
1.544(1.350-1.765) \\
1.058(0.850-1.317) \\
1.514(1.243-1.844) \\
0.767(0.539-1.091)\end{array}$ & $\begin{array}{l}0.004 \\
<0.0001 \\
0.171 \\
<0.0001 \\
0.613 \\
0.0001 \\
0.139\end{array}$ \\
\hline \multicolumn{3}{|l|}{ Lowest $\mathrm{P}_{\mathrm{a}} \mathrm{O}_{2} / \mathrm{F}_{\mathrm{i}} \mathrm{O}_{2}$ ratio } \\
\hline 200-300 (mild ARDS) & Reference & \\
\hline $\begin{array}{l}100-299 \text { (moderate ARDS) } \\
<100 \text { (severe ARDS) }\end{array}$ & $\begin{array}{l}1.229(1.094-1.381) \\
1.692(1.489-1.923)\end{array}$ & $\begin{array}{l}0.0005 \\
<0.0001\end{array}$ \\
\hline Highest $\mathrm{P}_{\mathrm{a}} \mathrm{CO}_{2}$ on day $1>50 \mathrm{mmHg}$ & $1.411(1.252-1.589)$ & $<0.0001$ \\
\hline Pulmonary ARDS & $0.680(0.595-0.775)$ & $<0.0001$ \\
\hline \multicolumn{3}{|c|}{ SOFA score without respiratory points on day 1} \\
\hline$<4$ & Reference & \\
\hline $\begin{array}{l}4-5 \\
5-8 \\
>8\end{array}$ & $\begin{array}{l}1.526(1.268-1.835) \\
2.329(1.961-2.766) \\
5.033(4.254-5.955)\end{array}$ & $\begin{array}{l}<0.0001 \\
<0.0001 \\
<0.0001\end{array}$ \\
\hline ICU-acquired events ${ }^{\mathrm{a}}$ & $1.411(1.252-1.589)$ & $<0.0001$ \\
\hline
\end{tabular}

ARDS acute respiratory distress syndrome, $\mathrm{HIV}$ human immunodeficiency virus, $\mathrm{PaO}_{2} / \mathrm{FiO}_{2}$ ratio of partial pressure of oxygen in arterial blood over fraction of inspired oxygen, $\mathrm{PaCO}_{2}$ partial pressure of carbon dioxide in arterial blood, SOFA Sequential Organ Function Assessment, ICU intensive care unit

a Defined as events that were not expected at ICU admission but may affect outcomes, i.e., bleeding, myocardial or mesenteric infarction, atelectasis, cardiac arrest, arrhythmia requiring cardioversion, pulmonary embolism, drug allergy, seizures, medical error, hypoglycemia, and pericarditis requiring drainage

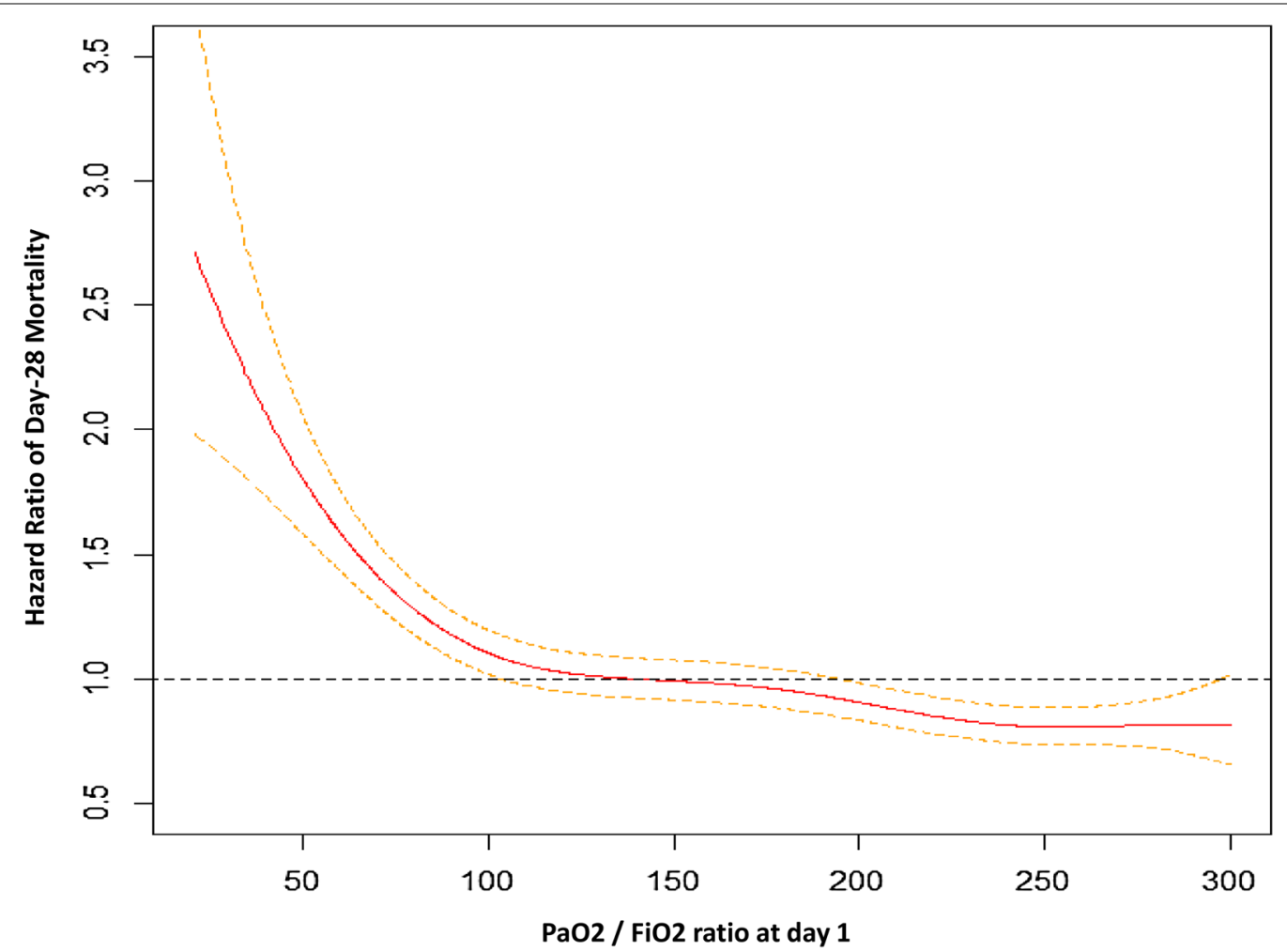

Fig. 3 Hazard ratio for day-28 mortality according to $\mathrm{P}_{2} \mathrm{O}_{2} / \mathrm{F}_{i} \mathrm{O}_{2}$ on day 1. The depicted spline is adjusted on comorbidities, SOFA score on day 1 without the respiratory subscore, and worst $\mathrm{PaCO}_{2}$ on day 1 

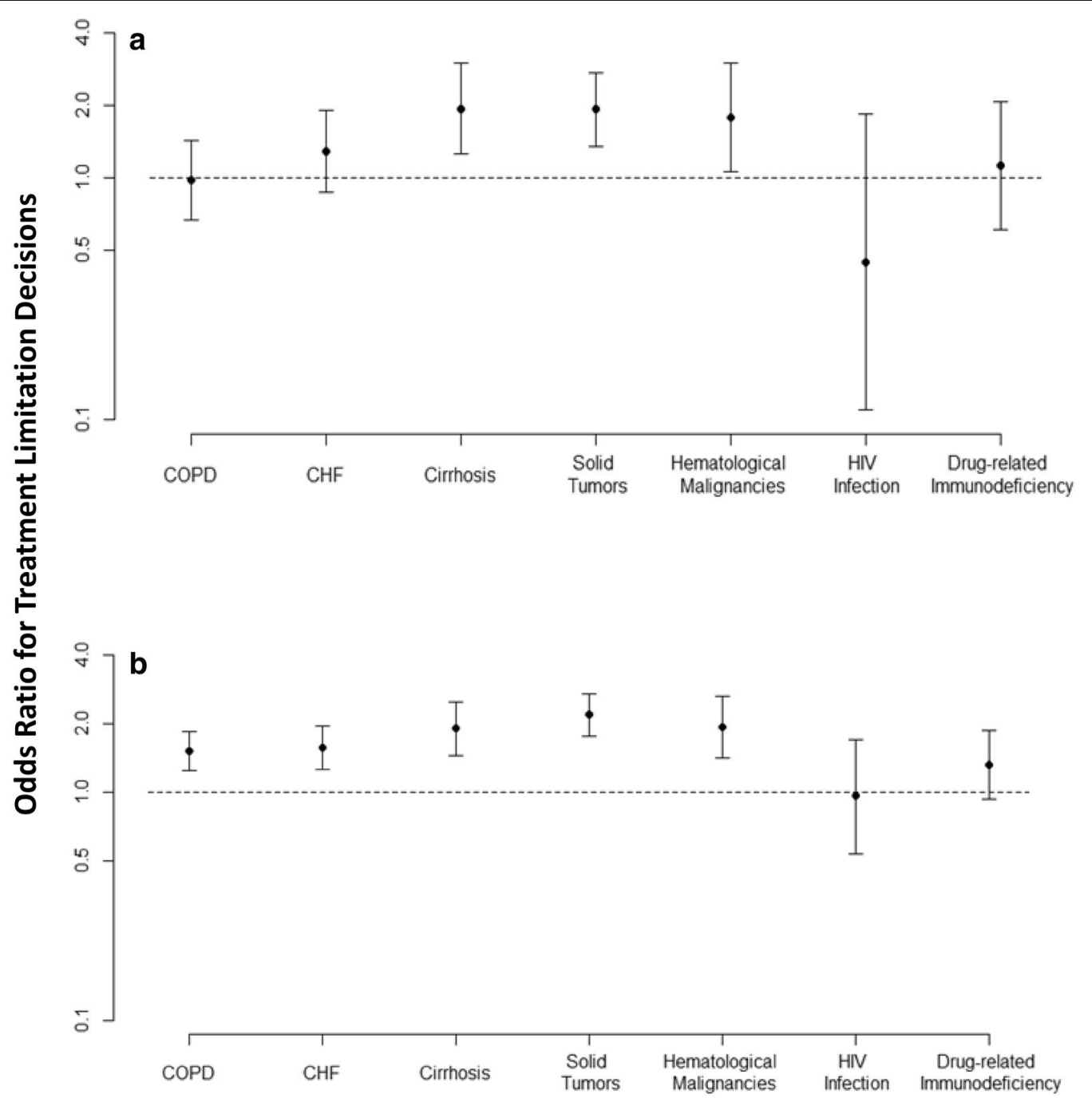

Fig. 4 Odds ratio for treatment-limitation decisions according to the comorbidity group. a Shows decisions made within 2 days after ICU admission and $\mathbf{b}$ decisions made at any time during the ICU stay. The reference group is the group without comorbidities. COPD chronic obstructive pulmonary disease, CHF chronic heart failure, HIV human immunodeficiency virus

without comorbidities, mortality rate remained unchanged between the two time periods. However, in patients with major comorbidities, mortality non-significantly decreased (Fig. 5). The number of patients on dialysis for end-stage renal failure was too small for a separate analysis.

\section{Discussion}

In an unselected population with ARDS in 1997-2014, half had major comorbidities and this proportion increased over time. In the group with major comorbidities, hypoxemia was more severe, extrapulmonary organ dysfunction more common, and ICU resource consumption greater. Presence of at least one major comorbidity was independently associated with higher day- 28 mortality. These findings suggest that ARDS trials excluding patients with major comorbidities actually hamper the generalizability of study findings that may not be generalizable to the whole ARDS population.

Patients admitted to the ICU today are older, more severely ill, and more likely to have chronic comorbidities compared to 20 years ago [26, 29]. Several factors may explain these changes, including the aging of the population [30] and the better survival among patients with cancer [31], cardiovascular disease [32], and chronic inflammatory disorders [33]. Due to therapeutic advances, many patients now live with chronic medications that impair their immune defenses [34]. A role for 


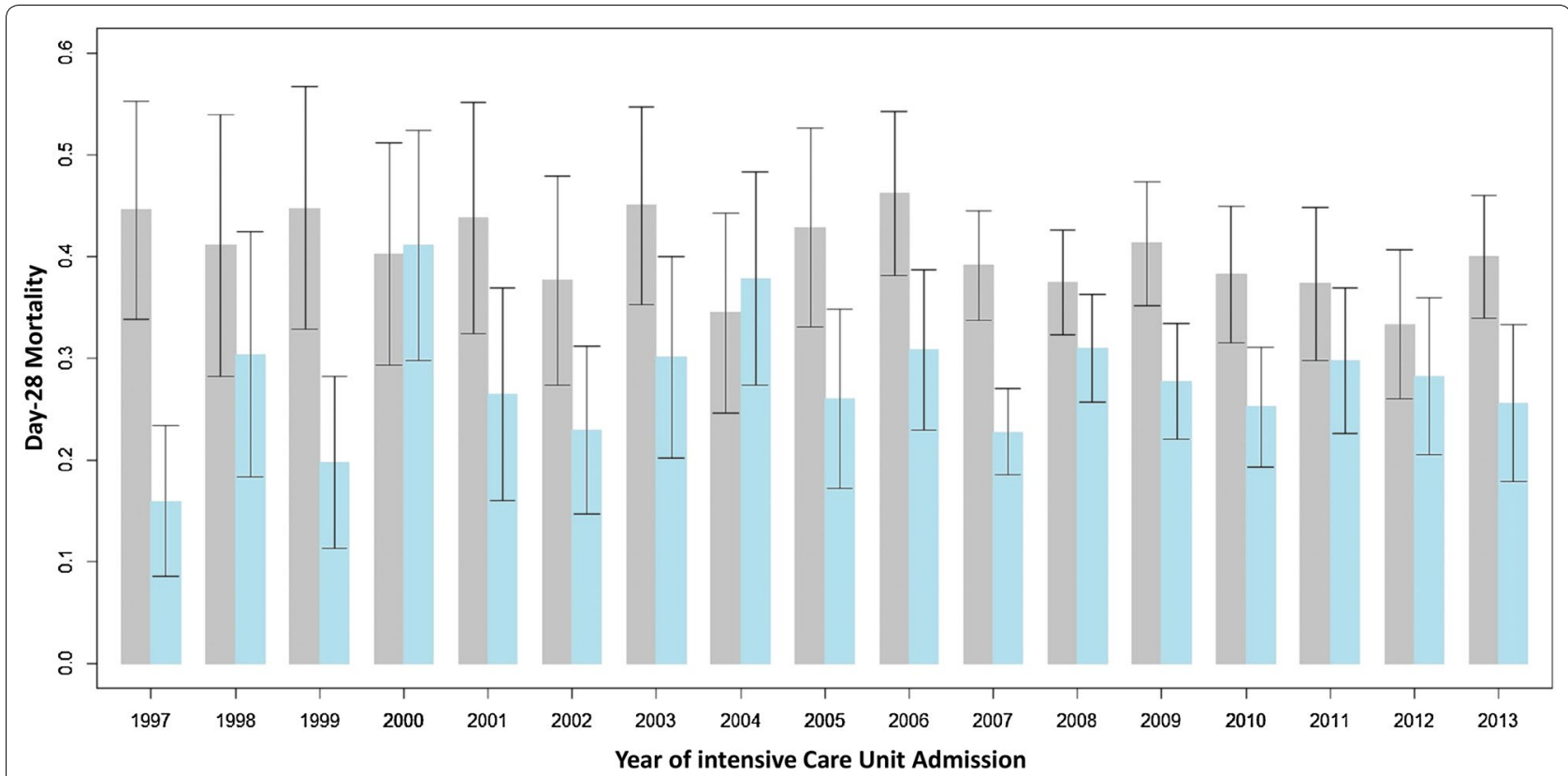

Fig. 5 Day-28 mortality (with 95\% confidence intervals) during each study year in patients with at least one comorbidity (gray bars) and those with no comorbidities (blue bars). The test for trend was non-significant in the group without comorbidities (Cochran-Armitage test, $P=0.46)$ and showed a non-significant trend in patients with at least one comorbidity (Cochran-Armitage test, $P=0.09)$

these factors is supported by our finding that half the patients with ARDS had major comorbidities and that this proportion increased over time. At present, these patients are denied enrolment into studies of treatments that may improve their short- and long-term survival, as well as their health-related quality of life [30], raising concerns and questions about the main goals of clinical research [35], which should be to improve patient survival and wellbeing [36].

Studies that exclude half the potentially eligible patients also raise methodological concerns about external validity. Most of the advances in ARDS management have stemmed from improvements in our understanding of pathophysiological mechanisms. There is no evidence that these mechanisms differ between patients with versus without comorbidities, and therefore no reason not to apply and to study the new treatments in patients with comorbidities. Moreover, the types of comorbidities used as exclusion criteria varied across studies, further aggravating concerns about external validity. Thus, only half the studies excluded patients with chronic respiratory failure. Finally, some patients with undiagnosed cancer, COPD, or liver disease may have been included in studies of ARDS.

Our findings indicate that including unselected ARDS patients may decrease the sample size needed to obtain the required number of events. Major clinical endpoints in ARDS research are respiratory and global severity, need for rescue strategies, ICU-acquired infectious or non-infectious events, and mortality [36]. All these endpoints were significantly more common in our patients with major comorbidities. The frequency differences suggest that sample sizes could be reduced by up to $30 \%$ if unselected patients were included. Smaller sample sizes improve the feasibility and decrease the costs of randomized controlled trials while also decreasing the risk of harm to patients [37].

Taken together, these arguments support the inclusion of patients with comorbidities in physiological and clinical studies of ARDS. Also, including unselected patients may allow to refine the clinical phenotypes of ARDS in terms of lung and systemic inflammatory patterns, pulmonary involvement (focal vs. diffuse or pulmonary vs. extrapulmonary), risk-stratification biomarkers, and response to treatments [38.] An alternative to apply strict exclusion criteria that hamper generalizability of the findings would be to use stratification. This method can be used to ensure equal allocation of subgroups of participants to each treatment group. This may be done for any comorbidity.

This study has several limitations. First, we neither assessed the treatment responses nor refined the clinical phenotypes. However, the large number of patients suggests hypotheses of potential usefulness for future ARDS research. Second, most of the recent advances in ARDS were provided by new insights into the mechanical, 
pathological, inflammatory, and immune-biological properties of the affected lungs. However, we did not have the data needed for comparisons of plateau, driving, or transpulmonary pressures across comorbidity groups. Neither could we compare lung morphology and pathology or ARDS biomarkers between patients with and without major comorbidities. Last, the exclusion criteria used in clinical trials are intended in part to maximize patient safety and to obtain uniform patient populations, although they also increase the chances of achieving efficacy endpoints. Nevertheless, using exclusion criteria that are highly prevalent is open to criticism. Other methodological tools are available, such as stratification on factors other than the study intervention, which facilitates the control of confounding factors and the detection and interpretation of relationships among variables.

In summary, our findings strongly suggest that including unselected patients in studies of ARDS would provide new information of greater relevance to clinical practice compared to studies done in the past, and give the most vulnerable patients access to potential benefits from experimental treatment strategies. Also, applying the available evidence to patients with comorbidities may show differences in responses to therapy and determinants of survival, thereby identifying new targets for improvement.

\section{Electronic supplementary material}

The online version of this article (https://doi.org/10.1007/s00134-018-5209-6) contains supplementary material, which is available to authorized users.

\begin{abstract}
Author details
${ }^{1}$ Medical Intensive Care Unit, AP-HP, Saint-Louis hospital, ECSTRA Team, Biostatistics and CLINICAL EPIDEMIOLOGY, UMR 1153 (Center of Epidemiology and Biostatistic Sorbonne Paris Cité, CRESS), INSERM, Paris Diderot Sorbonne University, Paris, France. ${ }^{2}$ Réanimation Médicale et Infectieuse, Hôpital Bichat Claude Bernard, Assistance Publique-Hôpitaux de Paris, Paris, France. ${ }^{3}$ Polyvalent Intensive Care Unit, Groupe Hospitalier Saint-Joseph, Paris, France. ${ }^{4}$ Service de Réanimation Médicale, Centre Hospitalier Universitaire GrenobleAlpes, CS10217, Grenoble Cedex 09, France. ${ }^{5}$ Department of Biostatistics, OUTCOMEREA ${ }^{\mathrm{TM}}$, Bobigny, France ${ }^{6}$ Medical ICU, Edouard Hériot University Hospital, Lyon, France. ${ }^{7}$ Medical-Surgical ICU, Bobigny University hospital, Paris, France. ${ }^{8}$ Medical Intensive Care Unit, Gabriel Montpied University Hospital, Clermont-Ferrand, France. ${ }^{9}$ Réanimation des Détresses Respiratoires et Infections Sévères, Hôpital Nord, Aix-Marseille University, Assistance PubliqueHôpitaux de Marseille, Unité de Recherche sur les Maladies Infectieuses et Tropicales Émergentes (URMITE), UMR CNRS 7278, Marseille, France. ${ }^{10}$ Medical Intensive Care Unit, Nantes University Hospital Center, Nantes, France. ${ }^{11}$ Surgical ICU, Edouard Herriot University Hospital, Lyon, France. ${ }^{12}$ Réanimation polyvalente-Surveillance Continue-Site d'Etampes, Centre hospitalier Sud Essonne (Etampes), Paris, France. ${ }^{13}$ Medical Surgical ICU, Centre hospitalier de Cayenne, Guyane, France. ${ }^{14}$ UMR 1137, Infection Antimicrobials Modelling Evolution (IAME) Team 5, Decision Sciences in Infectious Diseases (DeSCID), Control and Care, Sorbonne Paris Cité, Inserm/Paris Diderot University, Paris, France.
\end{abstract}

\section{Acknowledgements}

Members of the OUTCOMEREA Study Group: Scientific Committee, JeanFrançois Timsit: Medical and Infectious Diseases ICU, Bichat-Claude Bernard Hospita, Paris, France, UMR 1137 Inserm, Paris Diderot university IAME, F75018, Paris, France. Elie Azoulay, Medical ICU, Saint Louis Hospital, Paris, France.
Maïté Garrouste-Orgeas, ICU, Saint-Joseph Hospital, Paris, France. Jean-Ralph Zahar: Infection Control Unit, Angers Hospital, Angers, France. Christophe Adrie: Physiology, Cochin Hospital, Paris, France. Michael Darmon: Medical ICU, Saint Etienne University Hospital, St Etienne, France. Christophe, Clec'h: ICU, Avicenne Hospital, Bobigny, and UMR 1137 Inserm, Paris Diderot university IAME, F75018, Paris, France. Biostatistical and Information System Expertise: Jean-Francois Timsit: Medical and Infectious Diseases ICU, Bichat-Claude Bernard Hospital, Paris, France, UMR 1137 Inserm, Paris Diderot university IAME, F75018, Paris, France. Corinne Alberti: Medical Computer Sciences and Biostatistics Department, Robert Debré Hospital, Paris, France. Adrien Français: Integrated Research Center U823, Grenoble, France. Aurélien Vesin: OUTCOMEREA organization and Integrated Research Center U823, Grenoble, France. Stephane Ruckly: OUTCOMEREA organization and Inserm UMR 1137 IAME, F75018, Paris, France. Sébastien Bailly: Grenoble university hospital Inserm UMR 1137 IAME, F75018, Paris, France. Christophe Clec'h: ICU, Avicenne Hospital, Bobigny, and Inserm UMR 1137 IAME, F75018, Paris, France. Frederik Lecorre, Supelec, France. Didier Nakache: Conservatoire National des Arts et Métiers, Paris, France. Aurélien Vannieuwenhuyze: Tourcoing, France. Investigators of the OUTCOMEREA Database: RomainHernu: ICU, CH Melun, and Physiology, Cochin Hospital, Paris, France. Christophe Adrie. Carole Agasse: medical ICU, university hospital Nantes, France. Bernard Allaouchiche: ICU, Pierre benite Hospital, Lyon, France. Olivier Andremont: ICU, Bichat Hospital, Paris, France. Pascal, Andreu: CHU Dijon Dijon, France. Laurent Argaud: Medical ICU, Hospices Civils de Lyon, Lyon, France. Claire Ara-Somohano: Medical ICU, University Hospital, Grenoble, France. Elie Azoulay: Medical ICU, Saint Louis Hospital, Paris, France. François Barbier: medical-surgical ICU, Orleans, France. Déborah Boyer: ICU, CHU Rouen, France. Jean-Pierre Bedos: ICU, Versailles Hospital, Versailles, France. Thomas Baudry: Medial ICU, Edouard Heriot hospital, Lyon, France. JéromeBedel: ICU, Versailles Hospital, Versailles, France. Julien Bohé: ICU, Hôpital Pierre Benite, Lyon, France. Lila Bouadma: ICU, Bichat Hospital, Paris, France. Jeremy Bourenne: Réanimation des urgencies, Timone-2; APHM, Marseille, France. Noel Brule: medical ICU, university hospital Nantes, Nantes, France. Cédric Brétonnière: medical ICU, university hospital Nantes, Nantes, France. Christine Cheval: ICU, Hyeres HospitalHyeres, France. Julien Carvelli: Réanimation des urgencies, Timone-2; APHM, Marseille, France. Christophe Clec'h: ICU, Avicenne Hospital, Bobigny, France. Elisabeth Coupez: ICU, G Montpied Hospital, Clermont-Ferrand, France. Martin Cour: Medial ICU, Edouard Heriot hospital, Lyon, France. Michael Darmon: ICU, Saint Etienne Hospital, Saint Etienne, France. Etienne de Montmollin: ICU, Delafontaine Hospital, Saint Denis, France. Loa Dopeux: ICU, G Montpied Hospital, Clermont-Ferrand, France. Anne-Sylvie Dumenil: Antoine Béclère Hospital, Clamart, France. Claire Dupuis: Bichat hospital and UMR 1137 Inserm -Paris Diderot university IAME, F75018, Paris, France. Jean-Marc Forel: AP HM, Medical ICU, Hôpital Nord Marseille. Marc Gainnier: Réanimation des urgencies, Timone-2; APHM, Marseille, France. Charlotte Garret: medical ICU, university hospital Nantes, France. StevenGrangélCU, CHU Rouen, France. Antoine Gros: ICU, Versailles Hospital, Versailles, France. AkimHaouache: Surgical ICU, H Mondor Hospital, Creteil, France. RomainHernu: Medical ICU, Hospices Civils de Lyon, Lyon, France. Tarik Hissem: ICU, Eaubonne, France. Vivien Hon Tua Ha: ICU, CH Meaux, France. Sébastien Jochmans: ICU, CH Melun. Jean-Baptiste Joffredo: ICU, G Montpied Hospital, Clermont-Ferrand, France. Hatem Kallel: ICU, Cayenne General Hospital, Cayenne, France. Guillaume Lacave: ICU, Versailles Hospital, Versailles, France. Alexandre Lautrette: ICU, G Montpied Hospital, ClermontFerrand, France. Virgine Lemiale: Medical ICU, Saint Louis Hospital, Paris, France. Mathilde Lermuzeaux: ICU, Bichat Hospital, Paris, France. Guillaume Marcotte: Surgical ICU, Hospices Civils de Lyon, Lyon, France. Jordane Lebut: ICU, Bichat Hospital, Paris, France. MaximeLugosi: Medical ICU, University Hospital Grenoble, Grenoble, France. Eric Magalhaes: ICU, Bichat Hospital, Paris, France. Sibylle Merceron: ICU, Versailles Hospital, Versailles, France. Bruno Mourvillier: ICU, Bichat Hospital, Paris, France. Benoit Misset: ICU, Saint-Joseph Hospital, Paris, France, Medical ICU CHU Rouen, France. Bruno Mourvillier: ICU, Bichat Hospital, Paris, France. Mathild Neuville: ICU, Bichat Hospital, Paris, France. Laurent Nicolet: medical ICU, university hospital Nantes, France. Johanna Oziel: Medico-surgical ICU, hôpital Avicenne APHP, Bobigny, France. Laurent Papazian: Hopital Nord, Marseille, France. Benjamin Planquette: pulmonology ICU, George Pompidou hospital Hospital, Paris, France. Jean-Pierre Quenot: CHU Dijon, Dijon, France. Aguila Radjou: ICU, Bichat Hospital, Paris, France. Marie Simon: Medial ICU, Edouard Heriot hospital, Lyon, France. Romain Sonneville: ICU, Bichat Hospital, Paris, France. Jean Reignier: medical ICU, university hospital Nantes, France. Bertrand Souweine: ICU, G Montpied Hospital, ClermontFerrand, France. Carole Schwebel: ICU, A Michallon Hospital, Grenoble, France. 
Shidasp Siami: ICU, Eaubonne, France. Roland Smonig: ICU, Bichat Hospital, Paris, France. Gilles Troché: ICU, Antoine Béclère Hospital, Clamart, France. Marie Thuong: ICU, Delafontaine Hospital, Saint Denis, France. Guillaume Thierry: ICU, Saint-Louis Hospital, Paris, France. Dany Toledano: ICU, Gonesse Hospital, Gonesse, France. Guillaume Van Der Meersch: Medical Surgical ICU, university hospital Avicenne. Marion Venot: Medical ICU, Saint Louis Hospital, Paris, France. Olivier Zambon: medical ICU, university hospital Nantes, France. Study Monitors: Julien Fournier, Caroline Tournegros, Stéphanie Bagur, Mireille Adda, Vanessa Vindrieux, Sylvie de la Salle, Pauline Enguerrand, Loic Ferrand, Vincent Gobert, Stéphane Guessens, Helene Merle, Nadira Kaddour, Boris Berthe, Samir Bekkhouche, Kaouttar Mellouk, Mélaine Lebrazic, Carole Ouisse, Diane Maugars, Christelle Aparicio, Igor Theodose, Manal Nouacer, Veronique Deiler, Myriam Moussa, Atika Mouaci, Nassima Viguier and Sophie Letrou

\section{Author contributions}

$E A, J F T, M D$ and $V L$ designed the study and drafted the project, the manuscript and the managed the submission. JFT and SR audited the database, performed the statistical models and the validation of the score. BM, MGO, CS, $L P, Y C, B S, L A, J R, G M, S S$ and HK contributed to patient's recruitment, database audit and approved, edited and worked on the results, manuscript and submission. All authors included patients, discussed the plans and the models, reviewed, edited and agreed with the submitted version.

Received: 15 January 2018 Accepted: 5 May 2018

Published online: 7 June 2018

\section{References}

1. Papazian L, Calfee CS, Chiumello D, Luyt C-E, Meyer NJ, Sekiguchi H, Matthay MA, Meduri GU (2016) Diagnostic workup for ARDS patients. Intensive Care Med 42:674-685

2. Slutsky AS, Villar J, Pesenti A (2016) Happy 50th birthday ARDS! Intensive Care Med 42:637-639

3. Dreyfuss D, Soler P, Basset G, Saumon G (1988) High inflation pressure pulmonary edema. Respective effects of high airway pressure, high tidal volume, and positive end-expiratory pressure. Am Rev Respir Dis 137:1159-1164

4. Slutsky AS, Ranieri VM (2013) Ventilator-induced lung injury. N Engl J Med 369:2126-2136

5. Fan E, Del Sorbo L, Goligher EC, Hodgson CL, Munshi L, Walkey AJ, Adhikari NKJ, Amato MBP, Branson R, Brower RG, Ferguson ND, Gajic O, Gattinoni L, Hess D, Mancebo J, Meade MO, McAuley DF, Pesenti A, Ranieri VM, Rubenfeld GD, Rubin E, Seckel M, Slutsky AS, Talmor D, Thompson BT, Wunsch H, Uleryk E, Brozek J, Brochard L et al (2017) An Official American Thoracic Society/European Society of Intensive Care Medicine/Society of Critical Care Medicine Clinical Practice Guideline: mechanical Ventilation in Adult Patients with Acute Respiratory Distress Syndrome. Am J Respir Crit Care Med 195:1253-1263

6. Claesson J, Freundlich M, Gunnarsson I, Laake JH, Vandvik PO, Varpula T, Aasmundstad TA, Scandinavian Society of Anaesthesiology and Intensive Care Medicine (2015) Scandinavian clinical practice guideline on mechanical ventilation in adults with the acute respiratory distress syndrome. Acta Anaesthesiol Scand 59:286-297

7. Claesson J, Freundlich M, Gunnarsson I, Laake JH, Møller MH, Vandvik PO, Varpula T, Aasmundstad TA (2016) Scandinavian clinical practice guideline on fluid and drug therapy in adults with acute respiratory distress syndrome. Acta Anaesthesiol Scand 60:697-709

8. Ferguson ND, Fan E, Camporota L, Antonelli M, Anzueto A, Beale R, Brochard L, Brower R, Esteban A, Gattinoni L, Rhodes A, Slutsky AS, Vincent $J$-L, Rubenfeld GD, Thompson BT, Ranieri VM (2012) The Berlin definition of ARDS: an expanded rationale, justification, and supplementary material. Intensive Care Med 38:1573-1582

9. Pola MD, Navarrete-Navarro P, Rivera R, Fernández-Mondejar E, Hurtado B, Vázquez-Mata G (2000) Acute respiratory distress syndrome: resource use and outcomes in 1985 and 1995, trends in mortality and comorbidities. J Crit Care 15:91-96

10. Zilberberg MD, Epstein SK (1998) Acute lung injury in the medical ICU: comorbid conditions, age, etiology, and hospital outcome. Am J Respir Crit Care Med 157:1159-1164
11. Calfee CS, Delucchi K, Parsons PE, Thompson BT, Ware LB, Matthay MA, NHLBI ARDS Network. (2014) Subphenotypes in acute respiratory distress syndrome: latent class analysis of data from two randomised controlled trials. Lancet Respir Med 2:611-620

12. Bellani G, Laffey JG, Pham T, Fan E, Brochard L, Esteban A, Gattinoni L, van Haren F, Larsson A, McAuley DF, Ranieri M, Rubenfeld G, Thompson BT, Wrigge H, Slutsky AS, Pesenti A, LUNG SAFE Investigators, ESICM Trials Group (2016) Epidemiology, patterns of care, and mortality for patients with acute respiratory distress syndrome in intensive care units in 50 Countries. JAMA 315:788-800

13. Laffey JG, Madotto F, Bellani G, Pham T, Fan E, Brochard L, Amin P, Arabi Y, Bajwa EK, Bruhn A, Cerny V, Clarkson K, Heunks L, Kurahashi K, Laake JH, Lorente JA, McNamee L, Nin N, Palo JE, Piquilloud L, Qiu H, Jiménez JIS, Esteban A, McAuley DF, van Haren F, Ranieri M, Rubenfeld G, Wrigge H, Slutsky AS et al (2017) Geo-economic variations in epidemiology, patterns of care, and outcomes in patients with acute respiratory distress syndrome: insights from the LUNG SAFE prospective cohort study. Lancet Respir Med 5:627-638

14. Laffey JG, Bellani G, Pham T, Fan E, Madotto F, Bajwa EK, Brochard L, Clarkson K, Esteban A, Gattinoni L, van Haren F, Heunks LM, Kurahashi K, Laake JH, Larsson A, McAuley DF, McNamee L, Nin N, Qiu H, Ranieri M, Rubenfeld GD, Thompson BT, Wrigge H, Slutsky AS, Pesenti A, LUNG SAFE Investigators and the ESICM Trials Group (2016) Potentially modifiable factors contributing to outcome from acute respiratory distress syndrome: the LUNG SAFE study. Intensive Care Med 42:1865-1876

15. Bellani G, Laffey JG, Pham T, Madotto F, Fan E, Brochard L, Esteban A, Gattinoni L, Bumbasirevic V, Piquilloud L, van Haren F, Larsson A, McAuley DF, Bauer PR, Arabi YM, Ranieri M, Antonelli M, Rubenfeld GD, Thompson BT, Wrigge H, Slutsky AS, Pesenti A, LUNG SAFE Investigators, ESICM Trials Group (2017) Noninvasive ventilation of patients with acute respiratory distress syndrome. insights from the LUNG SAFE Study. Am J Respir Crit Care Med 195:67-77

16. Azoulay E, Pickkers P, Soares M, Perner A, Rello J, Bauer PR, van de Louw A, Hemelaar P, Lemiale V, Taccone FS, Martin Loeches I, Meyhoff TS, Salluh J, Schellongowski P, Rusinova K, Terzi N, Mehta S, Antonelli M, Kouatchet A, Barratt-Due A, Valkonen M, Landburg PP, Bruneel F, Bukan RB, Pène F, Metaxa V, Moreau AS, Souppart V, Burghi G et al (2017) Acute hypoxemic respiratory failure in immunocompromised patients: the Efraim multinational prospective cohort study. Intensive Care Med. https://doi. org/10.1007/s00134-017-4947-1

17. Azoulay $E$, Lemiale $V$, Mokart $D$, Pène $F$, Kouatchet $A$, Perez $P$, Vincent $F$, Mayaux J, Benoit D, Bruneel F, Meert A-P, Nyunga M, Rabbat A, Darmon M (2014) Acute respiratory distress syndrome in patients with malignancies. Intensive Care Med 40:1106-1114

18. Adda M, Coquet I, Darmon M, Thiery G, Schlemmer B, Azoulay E (2008) Predictors of noninvasive ventilation failure in patients with hematologic malignancy and acute respiratory failure. Crit Care Med 36:2766-2772

19. Azoulay E, Schlemmer B (2006) Diagnostic strategy in cancer patients with acute respiratory failure. Intensive Care Med 32:808-822

20. de Hemptinne Q, Remmelink M, Brimioulle S, Salmon I, Vincent J-L (2009) ARDS: a clinicopathological confrontation. Chest 135:944-949

21. Depuydt PO, Benoit DD, Vandewoude KH, Decruyenaere JM, Colardyn FA (2004) Outcome in noninvasively and invasively ventilated hematologic patients with acute respiratory failure. Chest 126:1299-1306

22. Frat J-P, Thille AW, Mercat A, Girault C, Ragot S, Perbet S, Prat G, Boulain T, Morawiec E, Cottereau A, Devaquet J, Nseir S, Razazi K, Mira J-P, Argaud L, Chakarian J-C, Ricard J-D, Wittebole X, Chevalier S, Herbland A, Fartoukh M, Constantin J-M, Tonnelier J-M, Pierrot M, Mathonnet A, Béduneau G, Delétage-Métreau C, Richard J-CM, Brochard L et al (2015) High-flow oxygen through nasal cannula in acute hypoxemic respiratory failure. $\mathrm{N}$ Engl J Med 372:2185-2196

23. Truche A-S, Darmon M, Bailly S, Clec'h C, Dupuis C, Misset B, Azoulay E, Schwebel C, Bouadma L, Kallel H, Adrie C, Dumenil A-S, Argaud L, Marcotte G, Jamali S, Zaoui P, Laurent V, Goldgran-Toledano D, Sonneville R, Souweine B, Timsit J-F, OUTCOMEREA Study Group (2016) Continuous renal replacement therapy versus intermittent hemodialysis in intensive care patients: impact on mortality and renal recovery. Intensive Care Med 42:1408-1417

24. Knaus WA, Draper EA, Wagner DP, Zimmerman JE (1985) APACHE II: a severity of disease classification system. Crit Care Med 13:818-829

25. Vincent JL, Moreno R, Takala J, Willatts S, De Mendonça A, Bruining H, Reinhart CK, Suter PM, Thijs LG (1996) The SOFA (Sepsis-related Organ 
Failure Assessment) score to describe organ dysfunction/failure. On behalf of the Working Group on Sepsis-Related Problems of the European Society of Intensive Care Medicine. Intensive Care Med 22:707-710

26. Vincent J-L, Marshall JC, Namendys-Silva SA, François B, Martin-Loeches I, Lipman J, Reinhart K, Antonelli M, Pickkers P, Njimi H, Jimenez E, Sakr Y, ICON investigators (2014) Assessment of the worldwide burden of critical illness: the intensive care over nations (ICON) audit. Lancet Respir Med 2:380-386

27. Garrouste-Orgeas M, Timsit JF, Vesin A, Schwebel C, Arnodo P, Lefrant JY, Souweine B, Tabah A, Charpentier J, Gontier O, Fieux F, Mourvillier B, Troché G, Reignier J, Dumay MF, Azoulay E, Reignier B, Carlet J, Soufir L, OUTCOMEREA Study Group (2010) Selected medical errors in the intensive care unit: results of the IATROREF study: parts I and II. Am J Respir Crit Care Med 181:134-142

28. Vesin A, Azoulay E, Ruckly S, Vignoud L, Rusinovà K, Benoit D, Soares M, Azeivedo-Maia P, Abroug F, Benbenishty J, Timsit JF (2013) Reporting and handling missing values in clinical studies in intensive care units. Intensive Care Med 39:1396-1404

29. Cabrera López C, Casanova Macario C, Marín Trigo JM, de-Torres JP, Sicilia Torres R, Sicilia Torres R, Polverino F, Divo M, Pinto Plata V, Zulueta JJ, Celli B (2017) Comparison of 2017 and and 2015 Global Initiative for Obstructive Lung Disease: Impact on Grouping and Outcomes. Am J Respir Crit Care Med. https://doi.org/10.1164/rccm.201707-1363oc

30. Thake M, Lowry A (2017) A systematic review of trends in the selective exclusion of older participant from randomised clinical trials. Arch Gerontol Geriatr 72:99-102

31. Siegel RL, Miller KD, Jemal A (2017) Cancer Statistics, 2017. CA Cancer J Clin 67:7-30

32. GBD 2016 Disease and Injury Incidence and Prevalence Collaborators (2017) Global, regional, and national incidence, prevalence, and years lived with disability for 328 diseases and injuries for 195 countries, 1990-2016: a systematic analysis for the global burden of disease study 2016. Lancet 390(10100):1211-1259. https://doi.org/10.1016/S0140 $-6736(17) 32154-2$

33. Harpaz R, Dahl RM, Dooling KL (2016) Prevalence of immunosuppression among US adults, 2013. JAMA 316(23):2547-2548. https://doi. org/10.1001/jama.2016.16477

34. Chetty R, Stepner M, Abraham S, Lin S, Scuderi B, Turner N, Bergeron A, Cutler D (2016) The association between income and life expectancy in the United States, 2001-2014. JAMA 315(16):1750-1766. https://doi. org/10.1001/jama.2016.4226

35. Crome P, Lally F, Cherubini A, Oristrell J, Beswick AD, Clarfield AM, Hertogh C, Lesauskaite V, Prada Gl, Szczerbińska K, Topinkova E, Sinclair-Cohen J, Edbrooke D, Mills G (2011) Exclusion of older people from clinical trials: professional views from nine European countries participating in the PREDICT study. Drugs Aging 28:667-677

36. Goligher EC, Amato MBP, Slutsky AS (2017) Applying precision medicine to trial design using physiology. Extracorporeal $\mathrm{CO}_{2}$ removal for acute respiratory distress syndrome. Am J Respir Crit Care Med 196:558-568

37. Guérin C, Papazian L, Reignier J, Ayzac L, Loundou A, Forel JM, investigators of the Acurasys and Proseva trials (2016) Effect of driving pressure on mortality in ARDS patients during lung protective mechanical ventilation in two randomized controlled trials. Crit Care 20(1):384. https://doi. org/10.1186/s13054-016-1556-2

38. Calfee CS, Delucchi K, Parsons PE, Thompson BT, Ware LB, Matthay MA, NHLBI ARDS Network (2014) Subphenotypes in acute respiratory distress syndrome: latent class analysis of data from two randomised controlled trials. Lancet Respir Med 2:611-620

39. Truwit JD, Bernard GR, Steingrub J, Matthay MA, Liu KD, Albertson TE, Brower RG, Shanholtz C, Rock P, Douglas IS, deBoisblanc BP, Hough CL, Hite RD, Thompson BT, National Heart, Lung, and Blood Institute ARDS Clinical Trials Network (2014) Rosuvastatin for sepsis-associated acute respiratory distress syndrome. N Engl J Med 370:2191-2200

40. Guérin C, Reignier J, Richard J-C, Beuret P, Gacouin A, Boulain T, Mercier E, Badet M, Mercat A, Baudin O, Clavel M, Chatellier D, Jaber S, Rosselli S, Mancebo J, Sirodot M, Hilbert G, Bengler C, Richecoeur J, Gainnier M, Bayle F, Bourdin G, Leray V, Girard R, Baboi L, Ayzac L, PROSEVA Study Group (2013) Prone positioning in severe acute respiratory distress syndrome. N Engl J Med 368:2159-2168

41. Ferguson ND, Cook DJ, Guyatt GH, Mehta S, Hand L, Austin P, Zhou Q, Matte A, Walter SD, Lamontagne F, Granton JT, Arabi YM, Arroliga AC,
Stewart TE, Slutsky AS, Meade MO, OSCILLATE Trial Investigators, Canadian Critical Care Trials Group (2013) High-frequency oscillation in early acute respiratory distress syndrome. N Engl J Med 368:795-805

42. Young D, Lamb SE, Shah S, MacKenzie I, Tunnicliffe W, Lall R, Rowan K, Cuthbertson BH, OSCAR Study Group (2013) High-frequency oscillation for acute respiratory distress syndrome. N Engl J Med 368:806-813

43. Rice TW, Wheeler AP, Thompson BT, deBoisblanc BP, Steingrub J, Rock P, NIH NHLBI Acute Respiratory Distress Syndrome Network of Investigators, NHLBI ARDS Clinical Trials Network (2011) Enteral omega-3 fatty acid, gamma-linolenic acid, and antioxidant supplementation in acute lung injury. JAMA 306:1574-1581

44. Rice TW, Wheeler AP, Thompson BT, Steingrub J, Hite RD, Moss M, Morris A, Dong N, Rock P, National Heart, Lung, and Blood Institute Acute Respiratory Distress Syndrome (ARDS) Clinical Trials Network (2012) Initial trophic vs full enteral feeding in patients with acute lung injury: the EDEN randomized trial. JAMA 307:795-803

45. Taccone P, Pesenti A, Latini R, Polli F, Vagginelli F, Mietto C, Caspani L, Raimondi F, Bordone G, lapichino G, Mancebo J, Guérin C, Ayzac L, Blanch L, Fumagalli R, Tognoni G, Gattinoni L, Prone-Supine II, Study Group (2009) Prone positioning in patients with moderate and severe acute respiratory distress syndrome: a randomized controlled trial. JAMA 302:1977-1984

46. Gao Smith F, Perkins GD, Gates S, Young D, McAuley DF, Tunnicliffe W, Khan Z, Lamb SE, BALTI-2 study investigators (2012) Effect of intravenous $\beta-2$ agonist treatment on clinical outcomes in acute respiratory distress syndrome (BALTI-2): a multicentre, randomised controlled trial. Lancet 379:229-235

47. Matthay MA, Brower RG, Carson S, Douglas IS, Eisner M, Hite D, Holets S, Kallet RH, Liu KD, Maclntyre N, Moss M, Schoenfeld D, Steingrub J, Thompson BT, National Heart, Lung, and Blood Institute Acute Respiratory Distress Syndrome (ARDS) Clinical Trials Network (2011) Randomized, placebo-controlled clinical trial of an aerosolized $\beta_{2}$-agonist for treatment of acute lung injury. Am J Respir Crit Care Med 184:561-568

48. Talmor D, Sarge T, Malhotra A, O'Donnell CR, Ritz R, Lisbon A, Novack V, Loring SH (2008) Mechanical ventilation guided by esophageal pressure in acute lung injury. N Engl J Med 359:2095-2104

49. Papazian L, Forel J-M, Gacouin A, Penot-Ragon C, Perrin G, Loundou A, Jaber S, Arnal J-M, Perez D, Seghboyan J-M, Constantin J-M, Courant P, Lefrant J-Y, Guérin C, Prat G, Morange S, Roch A, ACURASYS Study Investigators (2010) Neuromuscular blockers in early acute respiratory distress syndrome. N Engl J Med 363:1107-1116

50. Wheeler AP, Bernard GR, Thompson BT, Schoenfeld D, Wiedemann HP, deBoisblanc B, Connors AF, Hite RD, Harabin AL, National Heart, Lung, and Blood Institute Acute Respiratory Distress Syndrome (ARDS) Clinical Trials Network (2006) Pulmonary-artery versus central venous catheter to guide treatment of acute lung injury. N Engl J Med 354:2213-2224

51. Agarwal R, Srinivasan A, Aggarwal AN, Gupta D (2013) Adaptive support ventilation for complete ventilatory support in acute respiratory distress syndrome: a pilot, randomized controlled trial. Respirol Carlton Vic 18:1108-1115

52. Cornet AD, Groeneveld ABJ, Hofstra JJ et al (2014) Recombinant human activated protein $\mathrm{C}$ in the treatment of acute respiratory distress syndrome: a randomized clinical trial. PLoS ONE 9:e90983. https://doi. org/10.1371/journal.pone.0090983

53. Fernandez $R$, Trenchs $X$, Klamburg J et al (2008) Prone positioning in acute respiratory distress syndrome: a multicenter randomized clinical trial. Intensive Care Med 34:1487-1491

54. Hodgson CL, Tuxen DV, Davies AR et al (2011) A randomised controlled trial of an open lung strategy with staircase recruitment, titrated PEEP and targeted low airway pressures in patients with acute respiratory distress syndrome. Crit Care 15:R133

55. Meade MO, Cook DJ, Guyatt GH et al (2008) Ventilation strategy using low tidal volumes, recruitment maneuvers, and high positive end-expiratory pressure for acute lung injury and acute respiratory distress syndrome: a randomized controlled trial. JAMA 299:637-645

56. Mercat A, Richard J-CM, Vielle B et al (2008) Positive end-expiratory pressure setting in adults with acute lung injury and acute respiratory distress syndrome: a randomized controlled trial. JAMA 299:646-655

57. Villar J, Kacmarek RM, Pérez-Méndez L, Aguirre-Jaime A (2006) A high positive end-expiratory pressure, low tidal volume ventilatory strategy improves outcome in persistent acute respiratory distress syndrome: a randomized, controlled trial. Crit Care Med 34:1311-1318 